\title{
An Outbreak of Severe Acute Respiratory Syndrome-2019 (COVID-19): A Major Health Concern
}

\author{
Mohd Sajad ${ }^{1}$, Mofieed Ahmed ${ }^{2}$, Sonu Chand Thakur ${ }^{1, *}$ \\ ${ }^{1}$ Centre for Interdisciplinary Research in Basic Sciences (CIRBSc), Jamia Millia Islamia, New Delhi, INDIA. \\ ${ }^{2}$ Department of Biosciences, Jamia Millia Islamia, New Delhi, INDIA.
}

\begin{abstract}
In Wuhan City, the province of Hubei, China, there appeared an unusual epidemic of pneumonia of uncertain ethology in December 2019. A novel coronavirus was identified by the World Health Organisation (WHO) as the triggering agent and subsequently named COVID-19. Considered a relative of SARS, which infected the lower respiratory tract and manifested in people as pneumonia, COVID-19 is the product of a beta-Corona virus called SARS-COV-2. The frequency of COVID-19 infection continue to increase, with more than 278,467 deaths worldwide till May 9, 2020. To stop their further spread scientists and researchers are racing to investigate the nature of this virus and their effects. We summarize the current state of knowledge around COVID-19and the role of some dietary vitamins and immune enhancers that may help the immune system in fight against COVID-19. Moreover, it also highlights the impact of COVID-19 lockdown on pollution particularly in India, in response to this global outbreak.

Key words: COVID-19, Pandemic, Outbreak, Lockdown, Pollution, Nutrition.
\end{abstract}

\section{INTRODUCTION}

In Wuhan, China, a singular and alarmingly contagious primary bizarre (viral) pneumonia broke out in December 2019. It has been recognized as a zoonotic coronavirus, just like SARS coronavirus and MERS coronavirus and named COVID-2019. ${ }^{1}$ As of May 9, 2020, more than 4,067,427 cases of COVID-19 and 278,467 deaths had been mentioned, of which most cases and deaths have occurred in USA followed by Spain and Italy and UK (https://www. worldometers.info/coronavirus/). The coronavirus COVID-19 is affecting 203 countries and territories around the world and 2 international conveyance. Of those countries, the greatest number of deaths has occurred in USA, followed by UK, Italy, Spain, France, Brazil and Germany. This disease continuum is still established (including possibilities for asymptomatic spreading) and clinically assessed therapies have begun. Besides, the viral genome is being quickly replicated in the host body that needs to improve the diagnosis tests and also to prepare an effective vaccine against it. ${ }^{2}$ The review reviews prior guidelines for clinicians, includes an overview of what is understood, what is not understood and the next steps to resolve and avoid the epidemic. The analysis is focused on current facts. As of $9^{\text {th }}$ May 2020, 1,332,442 confirmed instances and 79,244 deaths had been stated in USA. The potential for these viruses to grow to become a deadly disease worldwide (pandemic) appears to be a life threatening problem. Regarding COVID-19, the WHO raised the hazard to the COV epidemic to the "very high" degree, on February 28, 2020. World governments are establishing countermeasures to stem viable devastating consequences. The scientists and the health workers around the arena work continuously to find the mode of transmission and symptoms, new diagnostics techniques prevention and healing techniques are rapidly developing. Many uncertainties stay concerning both the virus-host interplay and the evolution of the epidemic, with a
Submission Date: 09-05-2020; Revision Date: 07-07-2020; Accepted Date: 09-09-2020

DOI: 10.5530/ijper.54.4.176 Correspondence: Dr. Sonu Chand Thakur Centre for Interdisciplinary Research in Basic Sciences (CIRBSc), Jamia Millia Islamia, New Delhi-110025, INDIA.

Phone no: +91 9717278759 Email id: sthakur@jmi.ac.in

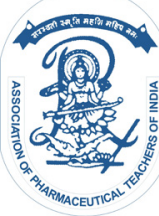

www.ijper.org 
particular connection with the times whilst the epidemic will reach its peak.

\section{TAXONOMY AND CLASSIFICATION OF CORONAVIRUS}

Both coronavirus and Toro virus belongs to the family Coronaviridae and these two members are morphologically similar. The Arteriviridae, Roniviridae and Coronaviridae are sharing the same order Nidovimles. To date, this coronavirus. Have been kept into one of three groups (Table 1). Four types of corona viruses namely NL63, HKU1, OC43 and 229E have been in circulation in humans with different symptoms and commonly cause the mild or severe respiratory disease. Their genome sequence is totally different from the previous strains present in human to that of the coronavirus that caused the SARS (CoV-SARS) outbreak. The Coronaviridae family contains more than a few viral species that can infect vertebrae, such as rodents, cattle, dogs, pigs, cats and poultry. ${ }^{3}$

\section{Structure and composition}

Coronavirus has a non-segmented, single-stranded RNA genome (Figure 1). These viruses are enveloped with a helical nucleocapsid. Prominent club-shaped spikes present on the surface of virus (corona) can be seen by electron microscope. In all these coronaviruses four types of structural proteins (Figure 1) are present - of these a

$\begin{gathered}\text { Table 1: Comparison of the Incubation period of } \\
\text { COVID-19 with other Viruses. }\end{gathered}$
\begin{tabular}{c|c|} 
Viruses & The incubation period (Typical Cases) \\
\hline COVID-19 & $2-14$ or $0-24$ days \\
\hline MERS & 5 days \\
\hline SARS & $2-7$ days but may extend to 10 days \\
\hline Seasonal flu & 2 days \\
\hline Swine flu & 4 days (some time up to 7 days) \\
\hline
\end{tabular}

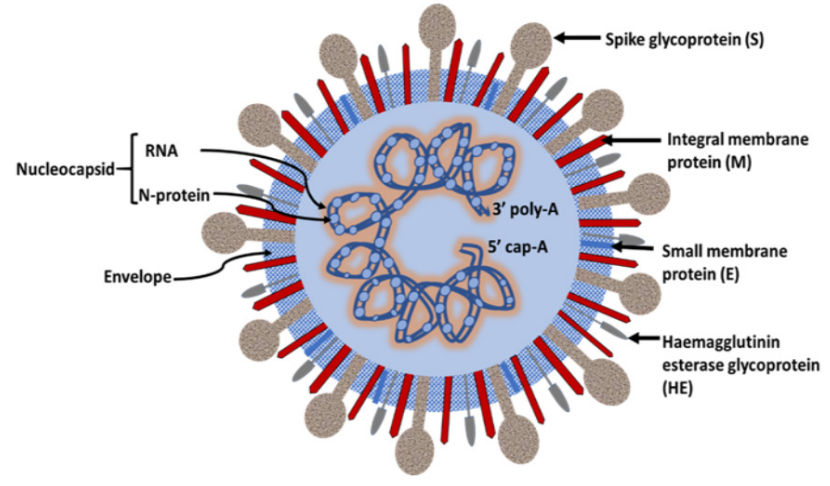

Figure 1: Structure of Coronavirus. large surface glycoprotein (S;1150-1450 amino acids), a medium protein envelope (E: 100 amino acids, found in minor quantities in virions), an embedded membrane glycoprotein (M:250 amino acids); and a phosphorylated nucleocapsid protein (N:500 amino acids) and also include additional structural glycoproteins, hem agglutininesterase. ${ }^{4}$ WHO and International Committee on Taxonomy of Viruses has given the name 2019-nCoV and SARS-CoV-2, this virus is a new human-infecting Beta coronavirus that is closely related with other 2 batderived SARS-like coronaviruses and it is likely to be originated from chrysanthemum bats.

The virus uses a strongly glycosylic (S) protein for accessing the host cells and binds in human beings similarly to SARS- with a high affinity of attraction to the receptor of angiotensin conversion enzyme 2 (ACE2). However, in initial time it has been seen the monoclonal antibodies don't show the binding pattern to the receptor site of SARS-COV-19 as compare to other SARS-COV, suggesting that this is a novel virus. The expression of enzyme ACE2 has seen in in type II alveolar cells and some findings have endorsed that the Asian males have a substantial quantity of ACE2expressing cells within the lung, which also show that predominance of COVID-19in male. However, some other causes, like higher smoking rates among men in China, may clarify the disparity in the sexual distribution of this condition. There is probably an intermediate host between bats and people and initial data show that it is the pangolin (a skale anteater), a threatened and commonly trafficked mammal that may have caused the recombination of a pangolin and bat coronaviruses. Several questions still remain unanswered that have implications for the public and clinical health, such as the emergence, transmission, vaccines and therapeutic procedure of this virus. ${ }^{5}$

\section{EPIDEMIOLOGY}

The standard incubation period of this virus ranges up to 14 days with a median 5 to 6 days. While recent reports suggest that it may last for 24 days $^{6}$ which is longer than the quarantine policies of $\mathrm{WHO}$ and the US Centres for Disease Control and Prevention (CDC). Theoretically the longer incubation period has a key effect on prevention of spread and quarantine policies. The virus seems mostly transmitted through large droplets but was also detected in stools and blood, which poses concerns about other potential transmission modes. ${ }^{7}$ If the virus can be transmitted by stool, various kinds of precautions may be needed. Healthassociated transmission, like other coronaviruses, tends 
to be one significant infection mode. The reproductive number (R0) of SARS-CoV-2, while still preliminary, is predicted to be between 2 and 3 and indicates a higher pandemic risk than SARS (the number of secondary cases generated by one infected individual in a susceptible population). It appears to be feasible for transmission from asymptomatic carriers ${ }^{6,7}$ may have significant consequences for screening and insulation if it is confirmed in larger studies. A study involving 9 pregnant patients indicates that perinatal transmission is impossible but more comprehensive experiments are needed to validate the finding. ${ }^{8}$ An estimation of nearly two-thirds of cases of COVID-19 transported from China remains undetected using evidence from air travel. ${ }^{\text {? }}$

\section{PATHOPHYSIOLOGY}

Coronaviruses mostly affect birds and rodents from the upper respiratory and gastrointestinal tracts. A crucial factor in the virulence of coronaviruses is surface spike glycoprotein (S-protein), as it is known to be able to bind to host cells. In SARS-CoV, the primary cellular receptor is human angiotensin-converting enzyme 2 (ACE2) and is suspected to play a role in SARS-CoV's capacity to develop upper and lower respiratory tract infections, leading to its lethality. ${ }^{10}$ Additionally, it has been shown that MERS-CoV binds to dipeptidyl-peptidase 4 (DPP4), a protein that was conserved across organisms known to harbour this coronavirus strain. Although most respiratory viruses infect ciliated cells, DPP4 is found in human airways non-ciliated cells, which is suspected to be an important factor in their zoonotic dissemination and high mortality rate. ${ }^{11}$ CoVS are +ve-stranded RNA virus enveloped with nucleocapsid. The genomic structure of CoVS, is organized in a +ssRNA of about $30 \mathrm{~kb}$ in length, the most important among the RNA viruses with 3'-poly-A tail and 5'-cap shape. The synthesis of polyprotein $1 \mathrm{a} / 1 \mathrm{ab}(\mathrm{pp} 1 \mathrm{a} / \mathrm{pp} 1 \mathrm{ab})$ start from the viral RNA inside the host. The transcription starts through the synthesis of sub-genomic RNAs (sgRNAs) sequences which is located in doublemembrane vesicles of replication-transcription complex (RCT). Transcription terminate at the transcription regulatory sequences, which is located between the open reading frames (ORFs) that acts as a template for the making of sub genomic miRNAs. Normally, at the least six ORFs segments are present in COV genome. Amongst these segments, a frame shift located between ORF1a and ORF1b directs the generation of each pp1a and pp1ab polypeptides which are being processed through virally encoded chymotrypsin-like protease (3clpro) or by most important protease (Mpro), in addition, to one or two papain-like proteases for producing sixteen non-structural proteins (nsps). Other than ORF1a and ORF1b, some other ORFs encode for structural proteins, inclusive of a membrane, spike, nucleocapsid proteins, accessory preotic chains and envelope. ${ }^{12}$ Exclusive CoVS presents unique structural as well as some accessory proteins which are translated through sgRNAs. The mechanisms of virulence and pathophysiology of CoVS and SARS-COV-2 have associated to the nsps and structural proteins function. For instance, some studies have highlighted that nsp has the ability to block the innate immune reaction of host. ${ }^{13}$ In the pathogenicity of virus, the envelope plays a key role amongst capabilities of structural proteins, because it promotes the assembly of virus. But, a lot of these capabilities (e.g., those of nsp 2 and 11) have now not yet been described. A number of the structural elements are also present in CoVS, these are the spike glycoproteins composed of subunits (S1 and S2). Of note, in SARS-Cov-2, the S2 subunit containing a trans membrane domain, a fusion peptide and cytoplasmic area is extremely preserved. Accordingly, it can be a goal for antiviral compounds (anti-S2). On the contrary, the binding sites of spike gives the best a $40 \%$ amino acid similarity with different SARS-CoVS. Different structural factors on which studies ought to always consider is the ORF3b that has no homology with secreted protein those encoded by using ORF8 and to that of SARS-CoVS, which is structurally different from those of SARS-COV.

In international gene banks, several gene sequences of Sars-COV-2 have been posted by different studies. This gene mapping is of fundamental significance allowing researchers to hint the phylogenetic tree of the virus and, primarily, the popularity of lines that range in step with the mutations. Consistent with recent studies, a spike mutation, which likely passed off in past due November 2019, triggered leaping to human beings. Especially, Angeletti et al. Compared the Sars-Cov-2 gene collection with that of SARS-COV. They analysed the trans membrane helical segments inside the ORF1ab encoded 2 (nsp2) and nsp3 and located that function 723 affords a serine rather than a glycine residue, whilst the placement 1010 is occupied by using proline in place of isoleucine. ${ }^{14}$ The matter of viral mutations is key for explaining ability disorder relapses. Studies might be needed to decide the structural traits of SARSCOV-2 that underlie the pathogen etic mechanisms. In comparison to SARS, for instance, preliminary scientific facts shows that this virus affects the respiration system 
more or less and due to lack of scientific studies it isn't possible to draw definitive clinical facts.

\section{SCREENING, DIAGNOSIS AND TESTING}

Both the WHO and the CDC recommend that the person diagnosed or under investigation for SARS-in 14 days with mild fever and /or other respiratory symptoms be screened in conjunction with traveling to China (especially to Hubei Province). However, given the increasing number of cases in other countries including South-Korea, Italy, Japan, India and Pakistan and the latest case study in California with no travel history or contact background with someone who travelled, will likely soon lead to changes in screening recommendations. Currently, testing facilities remains limited. CDC provided primers, samples and procedures, but test kits and efficiency challenges also hindered the scaling up of studies across several laboratories in public health. In the USA fewer than 500 experiments were conducted, based on data released on the CDC coronavirus site. Developing robust testing capabilities is an unmet need in confronting this outbreaks and essential for identification of those with infection and minimal symptoms. If a clinician is likely to recognize a possible case (i.e. a COVID-19 investigator), according to CDC's latest guidelines the clinician will contact a nearby public health laboratory to coordinate testing. The specimen sent for RT-PCR examination is an oral and a nasopharyngeal swab and/or a lower breath tract sample such as tracheal suction, speculated sputum, or bronchial lavage. It is advised that the test specimen be provided for RT-PCR. sSerum is no longer recommended for sampling and virus culture is also not allowed till date. Other tests should be conducted with standardized protocols in medical labs, such as full count and routine microbiology for blood cell and genetic examination for other respiratory viruses. ${ }^{5}$ COVID-19

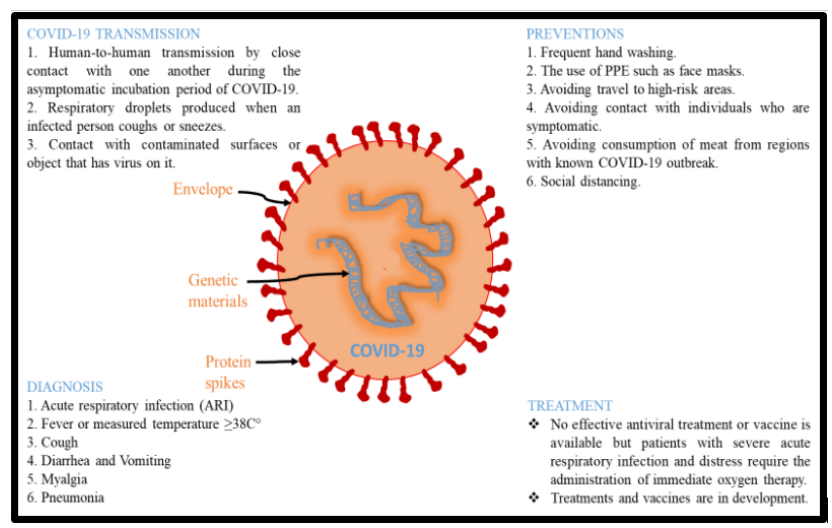

Figure 2: Illustrated the mode of transmission, diagnosis, prevention and treatment for COVID-19. has dry cough and fevers, nausea, vomiting and myalgia as clinical symptoms, Figure 2. Multiple comorbidity people can have a significant infection and acute kidney injury (AKI) and ARDS symptoms. ${ }^{15,16}$ Both WHO and CDC provided clinical and epidemiological guidelines on the main results of COVID-19. ${ }^{17}$ For patients with suspected infection, extensive laboratory tests should be requested. High $\mathrm{C}$ reactive protein, erythrocyte sedimentation, lactate dehydrogenase, creatinine and extended periods of pro-thrombi nation can be found in patients. ${ }^{18}$ Total genome sequencing and broncho alveolar fluid phylogenetic analyses will validate COVID-2019. ${ }^{19}$ Studies should also be carried out on other respiratory pathogens.

\section{PREVENTION AND TREATMENT}

Several organizations have been given guidance on avoiding the continued dissemination of COVID19 (https://www.cdc.gov/coronavirus/2019ncov/ about/transmission.html), (https://www.who.int/ emergencies/diseases/novel-coronavirus-2019/advicefor-public), including $\mathrm{WHO}$ and Centres for Disease Control and Prevention (CDC) Figure 2. They suggest restricting travel to high-risk locations, interacting with symptomatic persons and eating meat from established COVID-19 locations. Basic hygiene steps, including regular washing of hands and the use of PPE, such as face masks, are also recommended. Also, Japanese-based Bespoke Inc. is launching an artificial intelligence-enabled chatbot (Bebot) with up to date coronavirus outbreak information, preventative action and symptom checker. ${ }^{17}$ There is no specific treatment against this viral infection and yet there is no antibody is accessible as of now. The present treatment is based on symptoms and oxygen treatment is significant for patients in the thrilling stage. In case of respiratory failure, mechanical ventilation might be vital. On January 28, 2020, the WHO discharged a report outlining WHO rules and logical proof got from the treatment of past pandemics from HCoVs. This report tends to measures for perceiving and arranging patients with extreme intense respiratory illness; procedures for contamination avoidance and control; early strong treatment and checking; a rule for research centre conclusion; the board of respiratory failure and ARDS; septic shock management; inhibition of complications; handlings; and attentions for pregnant patients. Among these suggestions, we report the systems for tending to respiratory failure, including high-stream nasal oxygen (HFNO) and defensive mechanical ventilation or nonintrusive ventilation (NIV). 
Even though no antiviral medications have been endorsed, lopinavir/ritonavir alpha and interferon have been proposed. Preclinical investigations recommended that remdesivir (GS5734) which is an inhibitor of RNA polymerase have some in vitro properties against different RNA infections, like Ebola, could be successful for both treatment and prophylaxis of infections. ${ }^{11}$ This medication was emphatically tried against the MERSCOV infection in animal model. ${ }^{20}$

\section{NUTRITIONAL INTERVENTIONS}

\section{Vitamin A}

Vitamin A is the primary fat-soluble vitamin and $\beta$ carotene is its plant-derived precursor. There are three activated sources of vitamin A in the body and these are retinal, retinol and retinoic acids. Vitamin A is often referred to as "anti-infective" vitamin and its sufficient supply protect the body against various infection. ${ }^{21}$ The deficiency Vitamin A is closely linked with diarrhoea and measles. ${ }^{22}$ Furthermore, Semba et al. ${ }^{23}$ Specified that the supply of vitamin A decreased the morbidity and mortality ratio in multiple diseases such as diarrhoeal, measles, human immunodeficiency virus (HIV) and pneumonia. Vitamin A also show defensive mechanism against various chronic infections, such as lung diseases, HIV and malaria. ${ }^{24}$ Jee $\mathrm{J}$ et al..$^{25}$ Stated that the low quantity of Vitamin A in diets may lower the efficiency of inactivated BCV (bovine coronavirus vaccines). The consequence of Bronchitis Virus (IBV), which is a form of coronavirus, was more severe in chickens feed which have low quantity of Vitamin A than in those fed with sufficient Vitamin A diet. ${ }^{26}$ The process by which retinoid and Vitamin A prevent the development of measles is the upregulation of the innate immune response. Thus, Vitamin A may also be a good choice against lung infection caused by novel coronavirus.

\section{Vitamin B}

Vitamins B are coenzymes which is a water-soluble vitamin and each type has its own function. Vitamin $\mathrm{B}_{2}$ (riboflavin), plays a part in producing energy to cells. The deficiency of Vitamin $\mathrm{B}_{2}$ was alleged in the elderly in the United States. ${ }^{27}$ Keil SD et al. ${ }^{28}$ Stated that human plasma, vitamin $\mathrm{B}_{2}$ and UV light effectively decreased MERS-CoV infection. Vitamin $B_{3}$, also known as nicotinamide, kill the Staphylococcus aureus due to the activation of myeloid-specific transcription factor. In comparison, treatment with Vitamin $\mathrm{B}_{3}$ greatly reduced neutrophil accumulation in lungs due to its substantial anti-inflammatory activity. Paradoxically, though, it has also contributed to the production of severe hypoxemia. ${ }^{29}$ Vitamin $\mathrm{B}_{6}$ is often essential in protein synthesis and leads to more than 100 reactions in body tissues. Throughout fact, it also plays a significant part in the protective system of the body. As the lack of B vitamins that weaken the immune response of the host, virus-infected patients should be complemented to improve their immunity. Vitamin B may also be used as a simple alternative against COVID-19.

\section{Vitamin C}

It is a water-soluble vitamin which is also known as ascorbic acid. It is well recognized for its function in the formation collagen in the connective tissues that functions as an antioxidant. It also promotes several immune functions. This vitamin can also serve as a mild antihistamine agent to alleviate flu-like symptoms such as stuffy or runny nose, sneezing and enlarged sinuses. ${ }^{30}$ Three human controlled trials recorded a slightly lower prevalence of pneumonia in population with Vitamin C-supplementation, indicating that Vitamin $\mathrm{C}$ can reduce vulnerability to lower respiratory tract infections.

\section{Vitamin $E$}

Vitamin $\mathrm{E}$ is lipid-soluble that comprises both tocotrienols and tocopherols. Vitamin E shows a significant function in decreasing the oxidative stress by attaching to free radicals to an antioxidant. ${ }^{31}$ The deficiency of Vitamin $\mathrm{E}$ has been described to increase the myocardial damage by Coxsackievirus $\mathrm{B}_{3}$ (RNA virus) infection in experimental models ${ }^{32}$ and increase the virulence of this virus in mice is due to deficiency of selenium or vitamin $\mathrm{E} .{ }^{33}$

\section{Omega-3 polyunsaturated fatty acids}

PUFAs (Long chain polyunsaturated fatty acids) are essential inducer of adaptive immune response and inflammation. ${ }^{34}$ Omega-6 PUFAs and omega-3 mainly facilitate the pro-inflammatory and anti-inflammatory activity. These are the precursors of leukotrienes/ prostaglandins, resolvins/protectins, respectively. ${ }^{34,35}$ Begin M, et al. ${ }^{35}$ Researched plasma lipid rates in AIDS patients and observed a significant and unique loss of omega-3 long-chain PUFAs present at high concentrations in fish oils.

\section{Immuno-Enhancers}

\section{Interferons}

Interferon's (IFNs) are classified into two types; Type I and Type II Interferon's. Being a member of IFN Category I, the IFN- $\alpha$ is developed very rapidly during an innate immune response against a viral infection. The IFN- $\alpha$ prevents the replication process in coronavirus. ${ }^{36,37}$ The in vitro study has showed that 
the Type I interferon's, like IFN- $\beta$, may inhibit the process of replication in SARS-CoV. ${ }^{38}$ Nevertheless, interferon- $\gamma$ has not been reported to have antiviral action against these SARS coronavirus. Kuri T, et al. ${ }^{39}$ Further stated that the IFN had been inhibited the transcription of SARS-CoV-in infected tissue cells and these cells had been able to partially recover their innate immune response to SARS-CoV after priming little quantity of IFNs.

\section{Thymosine $\alpha-1$}

Thymosine $\alpha-1$ (Ta1) is a thymic peptide hormone that has a unusual capacity to re-establish the homeostasis of immune system. ${ }^{40}$ It was for the first time extracted from the thymic tissue in the mid-sixties that attracted considerable interest for its immunostimulatory activity. ${ }^{41}$ It was also chemically synthesized and used against various disorders where immune response was impaired or disrupted. ${ }^{42}$ Thymosin $\alpha-1$ may often be consider as an enhancer of immune system in patients infected with SARS and seen to be successful in preventing the disease spread. Methylprednisolone was also used during the current diagnosis of COVID-19. But, before the use of methylprednisolone, the use of thymosin $\alpha 1$ is prudent. ${ }^{43}$

\section{Thymopentin (TP5)}

Thymopentin (TP5, munox), which is a synthetic pentapeptide, has been revealed to improve the production of antibody in old mice. In addition, it can boost the response of antibody in humans as well when administered subcutaneously $(50 \mathrm{mg}) .^{44}$ In addition, thymopentin can also be consider as an adjuvant for non-responsive or hypo responders to hepatitis B vaccination.

\section{Levamisole}

Levamisole is a low-molecular-weight synthetic molecule. It is the first member of a new class of drugs that can improve cell immunity in healthy, stable laboratory animals. ${ }^{45}$ Though, levamisole can either serve as an immunosuppressive agent or an immunostimulant agent depending on the timing and dose. Therefore, its therapeutic application must be significantly regarded. The use of levamisole and ascorbic against the stressed helper / inducer subpopulation of lymphocytes can reversed in measles in vitro experiments by acid therapy ${ }^{46}$ Thus, the usage of levamisole can also be recommended for the diagnosis of COVID-19.

\section{Intravenous gamma globulin (IVIg)}

Intravenous gamma globulin (IVIg) was initially produced in late $1970 \mathrm{~s}^{47}$ and is currently the best immunomodulating medication suitable for enduring use across all ages. During the 2003 SARS epidemic, IVIg was commonly used in Singapore. Though, one-third of seriously ill patients experienced venous thromboembolism, that include pulmonary embolism, following the usage of low-molecular weight heparin prophylactics. ${ }^{48}$ This was attributed to an improvement in IVIg-induced viscosity in hypercoagulable SARS patients.

\section{CURRENT WORLDWIDE SCENARIO OF SARS-COV-2}

This novel virus is part of the subgenus Sarbecovirus of the Orthocoronavirinae subfamily and is entirely distinct from the viruses responsible for the Middle East respiratory coronavirus syndrome (MERS-CoV) and the extreme acute respiratory coronavirus syndrome (SARSCoV). ${ }^{49}$ The recently developed SARS-CoV-2 (2019$\mathrm{nCoV}$ ) is part of the coronavirus community $2 \mathrm{~B} .{ }^{50}$ The SARS-CoV-2 genome sequences collected from patients show a 79.5 per cent sequence resemblance to that of SARS-CoV. ${ }^{51}$ A total of 4,067,427 cases of COVID-19 (with 2,78,467 deaths) have been recorded worldwide as of $9^{\text {th }}$ May 2020 (Figure 3). The epicentre of the latest SARS-CoV-2 (USA) recorded a record death associated with COVID-19.

In the present situation, USA, Spain, Italy, UK and France carries much of the risk of disease morbidity and mortality correlated with COVID-19 relative to other countries. The epidemic of COVID-19 was also correlated with a major economic effect internationally owing to the abrupt disruption in world commerce and supply chains that caused international corporations to make difficult choices that lead to substantial economic losses. The significant rise in the amount of reported critically ill patients with COVID-19 has now exceeded acute care stocks, restricting intensive care facilities to

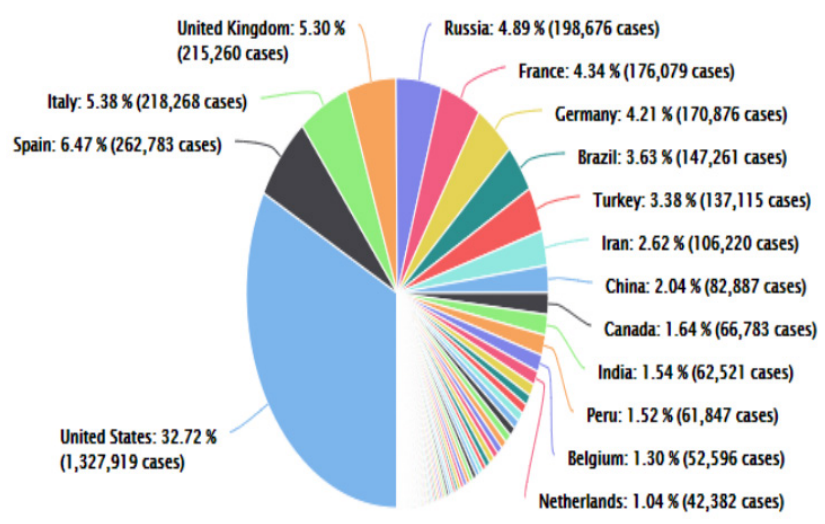

Figure 3: Showing the Total number of cases at world level (9th of May 2020) [https://www.worldometers.info/coronavirus/]. 
just a limited percentage of seriously sick patients. That may also have led to the rise in the cases of fatality reported in the COVID-19 Pandemic (https://www. worldometers.info/coronavirus/).

\section{COVID-19 AND INDIA}

On 30 January 2020, India confirmed the first outbreak of the 2019-20 coronavirus pandemic from China. By $9^{\text {th }}$ May 2020, a total of 59,662 cases, 17,846 recoveries, 1 relocation and 1981 deaths were reported throughout the country by the Indian Council for Medical Research and the Ministry of Health and Family Welfare. The COVID-19 infection rate is registered as 1.7 which is slightly lower than in the worst-affected countries. In more than a dozen states and Union territories, the outbreak has been proclaimed a disease emergency, where it has been enacted under terms of the Infectious Disease Act, 1897 and educational establishments and other business establishments have been shut

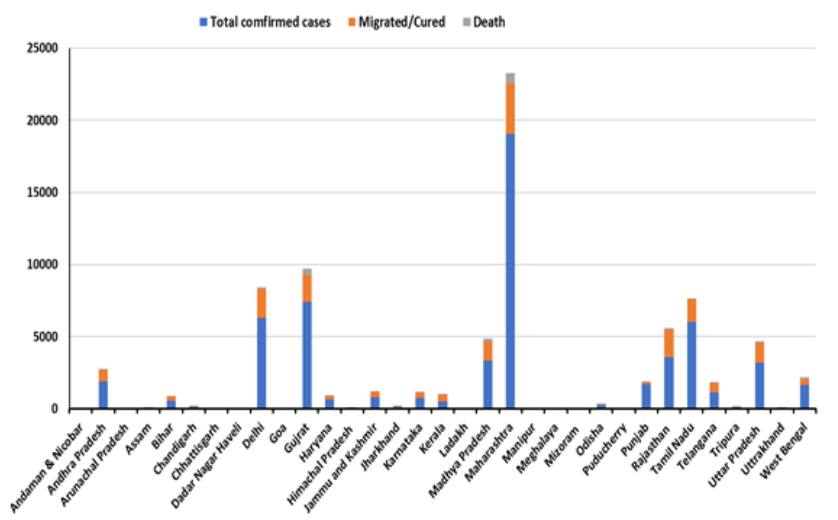

Figure 4: Depicts the state-wise cases, recoveries and deaths due to COVID-19 in India (https://www.mohfw.gov.in/).

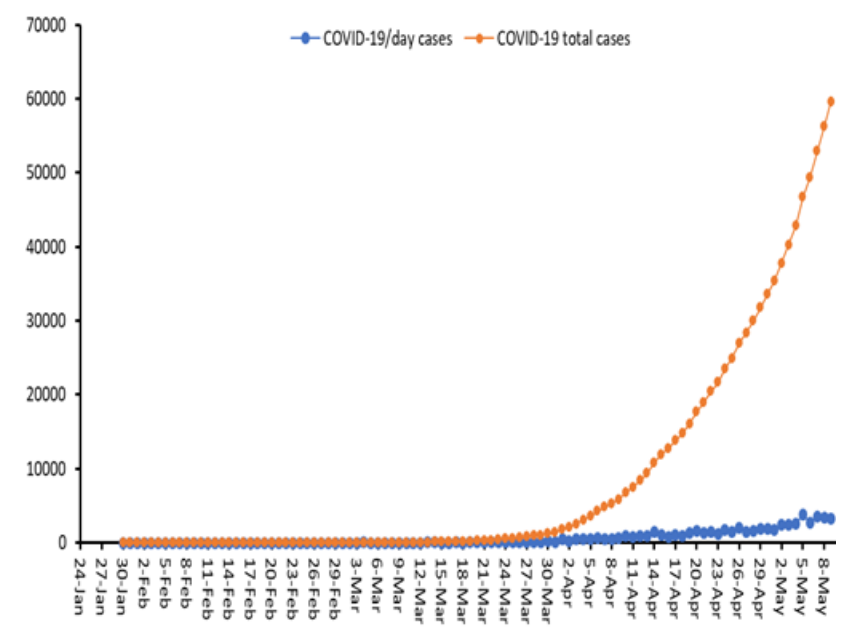

Figure 5: Represent the day-wise cases along with total cases of COVID-19 in India from the 30th of January 2020 to 9th of May 2020 (https://www.mohfw.gov.in/). down. India has revoked all tourist visas because most confirmed cases have also been associated with other countries that registered confirmed cases of COVID-19. Besides, entire country has been complete lockdown in different phases, till $17^{\text {th }}$ May 2020. The total of confirmed cases in India (state wise and Day wise) has been shown in (Figure 4 and 5). Maharashtra and Gujarat have the greatest number of cases so for [https://www.mohfw.gov.in/].

\section{LOCKDOWN EFFECT ON AIR AND WATER POLLUTION}

Air pollution has become a rising concern all over the globe, particularly in emerging nations like India. India observed rapid expansion of cities, economic growth, development of infrastructure and industrialization, since 1990s. At the same time, the air pollution level has increased in India and causes premature mortality due to major health problems. In India, pollution due to ambient particulate matter causes death of around one million people in 2015. ${ }^{52}$ According to Central Pollution Control Board (CPCB) and World Health Organization (WHO), due to the exceeding standard of ambient air quality, half of the top twenty most polluted cities are in India. ${ }^{53}$ Elevated levels of PM pose continuous threat to environment and human health. In India $\mathrm{PM}_{2.5}$ exposure accounted $25.7 \%$ of total global premature death in 2015. Moreover, in the Indian capital $\mathrm{PM}_{2.5}$ levels exceeds WHO set limits that results in $6.5 \%$ excess death. ${ }^{54}$

Due to contamination of COVID-19, lockdown was imposed in many countries. In India, first nationwide lockdown was imposed on $22^{\text {nd }}$ March for $14 \mathrm{hr}$, which was continued up to $14^{\text {th }}$ April and then extended up to $3^{\text {rd }}$ May and then further extended up to $17^{\text {th }}$ May. (https://www.mohfw.gov.in/). The lockdown and self-quarantine restrictions decreases emission from industries and transportation. By this, the air quality in most polluted cities across the country drastically improved and level of $\mathrm{PM}_{2.5}$ starts to drop according to CPCB. Due to lockdown, 1.3 billion Indians are forced to stay home and all the public transport such as buses, metro trains and interstate train, international and domestic flights have been stopped. All these restrictions and lockdown measures play major role in overcoming the problem of air pollution as well as restoration of air quality. Further, these measures provide opportunity to control air pollution in the future. According to CPCB, the nitrogen dioxide level in environment is decreased up to $71 \%$. According to Jyoti Pande Lavakare, the co-founder of Indian Environmental Organization Care 
for Air, "I have not seen such blue skies in Delhi for the past 10 years"(reported by $\mathrm{CNN}$ ). In short, the drastic reduction of environment pollution due to lockdown measures provides opportunity to control pollution in future if required.

On the other hand, the hydrosphere that includes oceans, rivers, lakes and ground water reservoirs has been severely polluted due to rapid overexploitation, industrialization and urbanization. Through nationwide lockdown, the sources of hydrosphere pollution such as plastics, heavy metals, crude oil and industrial wastewater disposal have been completely stopped. Hence, the pollution level is predicted to be reduced. According to some sources and experts, the health of the Ganga River has improved significantly along with its two tributaries, Hindon and Yamuna, due to reduction in dumping of industrial effluent into it. Likewise, the Karnataka State Pollution Control Board (KSPCB) has stated that the Cauvery and its tributaries are regaining their water quality. The industrial effluent in the Mumbai region has reduced in volume by 50 percent due to lockdown and has also breathed life into polluted creeks and rivers. (The Economic Times, The Times of India, The Hindu). According to environmental scientist BD Joshi "The remarkable level of purity is due to the absence of any industrial pollutants and garbage. It is after a long time the water quality of the Ganga River has become good for ritual sipping. In some stretches, the water has also become fit for drinking after its quality has been tested at different parameters. Such a remarkable improvement has not been witnessed in the past 30-40 years" (India Today). Further, the Uttarakhand Environment Protection and Pollution Board has also confirmed that there has a reduction in faecal coliform up to $34 \%$ and biochemical oxygen demand up to $20 \%$ in Haridwar. Moreover, the Uttar Pradesh Pollution Control Board (UPPCB), the dissolved oxygen level in healthy water should have at least $7 \mathrm{mg} /$ litre. In the present time the level of dissolved oxygen in Ganga River in upstream is up to $8.9 \mathrm{mg}$ per litre, while it is $8.3 \mathrm{mg}$ per litre in the downstream region. Thus, it is clear from all these facts that quality of water has improved substantially and is best for bathing and other livelihood. Moreover, under the Namami Ganga project, the Sisamau drain was totally stopped last year which has been used to discharge dirty effluents into the river from few decades. This has also brought down the pollution level in this water body but the recent improvement due to this lock down has unprecedented. The health of Ganga river has certainly improved in lockdown which several government's projects couldn't do in past (https://www.indiatoday.in).
According to BD Tripathi, chairman of the Mahamana Malviya Research Centre for Ganga, River Development and Water Resource Management at Banaras Hindu University (BHU), the water samples of Ganga which has been collected before and after few weeks of lockdown (March 24 and April 20) showed that the level of pollution had decreased significantly by $25 \%$ to $30 \%$. They also found that the concentration of dissolved oxygen (DO) raised by $20-30 \%$ and the concentration of biochemical oxygen demand has decreased by $35-40 \%$ (https://www.hindustantimes.com).

\section{FUTURE PROSPECTIVE}

The outlook of the COVID-19 outbreak remains uncertain. Despite case studies of COVID-19 transmission from asymptomatic carriers, its dissemination and containment must face extraordinary challenges. Regular awareness (and misinformation) has alerted both the general public and the scientific profession to the threats faced. People should follow the information given by the CDC or WHO and should avoid social media and other unverified sources for information to reduce the panic situation. The Lancet also published an article regarding such information and awareness that can be assessed through this link, (https://www.thelancet.com/action/showPdf?pii $=$ S0140-6736\%2820\%2930379-2).

\section{CONCLUSION}

The latest epidemic of COVID-19 has been considered an emergency in world health. Internationally, there have been further findings and 4,067,427 scientifically confirmed cases have already been identified and more than 2,78,467 deaths have been identified so for. Quarantine alone may not be enough to deter the dissemination of COVID-19, so it is a matter of heightened concern that this viral outbreak has a global effect. There is, of course, a need for further work to identify the exact processes of infection between man and human beings to promote the development of a particular virus vaccine. COVID-19's pandemic risk needs strict oversight and constant surveillance such that its possible host development, growth, interactions and pathogenicity can be tracked reliably and possibly. Ultimately, these causes can influence mortality rates and forecasts. Nevertheless, this analysis has been significantly constrained by the constantly evolving complexity of the COVID-2019 outbreak, the everchanging estimates and the relentless unravelling of recent scientific results. However, it is also our duty as an operational system to be aware of the abovedescribed signs and symptoms and to raise suspicious 
cases promptly. Further COVID-19 may also have some significant impact on pollution. The pollution control board of India has highlighted that there is a drastic change in air and surface water quality. In controlling different pollution, the lockdown strategy may be a future prospective if required.

\section{ACKNOWLEDGEMENT}

The authors acknowledge Dr. Sonu Chand Thakur for her valuable suggestion.

\section{CONFLICT OF INTEREST}

Authors declare no conflict of interest.

\section{ABBREVIATIONS}

WHO: World Health organization; SARS: Severe Acute Respiratory Syndrome; COVID-19: Coronavirus Disease - 2019; MERS: Middle East Respiratory Syndrome; ACE2: Angiotensin Conversion Enzyme 2; CDC: Centres for Disease Control and Prevention; DPP4: Dipeptidyl-peptidase 4; RCT: Replicationtranscription Complex; ORFs: Open reading frames; RT-PCR: Reverse transcription polymerase chain reaction; ARDS: Acute respiratory distress syndrome; AKI: Acute kidney injury; HFNO: High-stream nasal oxygen; NIV: Non-intrusive ventilation; HIV: Human Immunodeficiency Virus; BCV: Bovine Coronavirus Vaccines; IBV: Infectious Bronchitis Virus; PUFAs: Polyunsaturated fatty acids; IFNs: Interferons; CPCB: Central Pollution Control Board; PM: Particulate matter; KSPCB: Karnataka State Pollution Control Board; UPPCB: Uttar Pradesh Pollution Control Board.

\section{REFERENCES}

1. Wu Z, McGoogan JM. Characteristics of and important lessons from the coronavirus disease 2019 (COVID-19) outbreak in China: Summary of a report of 72314 cases from the Chinese Centre for Disease Control and Prevention. Jama. 2020;323(13):1239-42.

2. DelRio C, Malani PN. 2019 Novel coronavirus-important information for clinicians. Jama. 2020;323(11):1039-40

3. Gorbalenya AE. Severe acute respiratory syndrome-related coronavirus-The species and its viruses, a statement of the Coronavirus Study Group. Bio Rxiv. 2020.

4. Liu SQ, Zhang B. Zika virus: A flavivirus caused pandemics in Latin America. Virol Sin. 2016;31(2):101-2.

5. DelRio C, Malani PN. COVID-19-new insights on a rapidly changing epidemic. Jama. 2020;323(14):1339-40.

6. Bai Y, Yao L, Wei T, Tian F, Jin DY, Chen L, et al. Presumed asymptomatic carrier transmission of COVID-19. Jama. 2020;323(14):1406-7.

7. Zhang $\mathrm{W}$, Du RH, Li B, Zheng XS, Yang XL, Hu B, et al. Molecular and serological investigation of 2019-nCoV infected patients: Implication of multiple shedding routes. Emerging Microbes and Infections. 2020;9(1):3869.
8. Chen H, Guo J, Wang C, Luo F, Yu X, Zhang W, et al. Clinical characteristics and intrauterine vertical transmission potential of COVID-19 infection in nine pregnant women: a retrospective review of medical records. The Lancet. 2020;395(10226):809-15.

9. Bhatia S, Imai N, Cuomo-Dannenburg G, Baguelin M, Boonyasiri A, Cori A, et al. Report 6: Relative sensitivity of international surveillance. Imperial College. 2020.

10. Lam CY. Comparative molecular analysis of the binding between severe acute respiratory syndrome coronavirus (SARS-CoV) spike protein and angiotensin converting enzyme 2 (ACE2). 香港大學學位論文. 2007;1-0.

11. Kleine-Weber H, Schroeder S, Krüger N, Prokscha A, Naim HY, Müller MA, et al. Polymorphisms in dipeptidyl peptidase 4 reduce host cell entry of Middle East respiratory syndrome coronavirus. Emerging Microbes and Infections. 2020;9(1):155-68.

12. Perlman S, Netland J. Coronaviruses post-SARS: update on replication and pathogenesis. Nature Reviews Microbiology. 2009;7(6):439-50.

13. Lei J, Kusov Y, Hilgenfeld R. Nsp3 of coronaviruses: Structures and functions of a large multi-domain protein. Antiviral Research. 2018;149:58-74.

14. Angeletti S, Benvenuto D, Bianchi M, Giovanetti M, Pascarella S, Ciccozzi M. COVID-2019: The role of the nsp2 and nsp3 in its pathogenesis. Journal of Medical Virology. 2020;92(6):584-8.

15. Kute V, Godara S, Goplani K, Gumber M, Shah P, Vanikar A, et al. High mortality in critically ill patients infected with 2009 pandemic influenza A (H1N1) with pneumonia and acute kidney injury. Saudi Journal of Kidney Diseases and Transplantation. 2011;22(1):83.

16. Huang $\mathrm{C}$, Wang $\mathrm{Y}, \mathrm{Li} \mathrm{X}$, Ren L, Zhao J, Hu Y, et al. Clinical features of patients infected with 2019 novel coronavirus in Wuhan, China. The Lancet. 2020;395(10223):497-506.

17. Sohrabi C, Alsafi Z, O'Neill N, Khan M, Kerwan A, Al-Jabir A, et al. World Health Organization declares global emergency: A review of the 2019 novel coronavirus (COVID-19). International Journal of Surgery. 2020;76:71-6.

18. Wang D, Hu B, Hu C, Zhu F, Liu X, Zhang J, et al. Clinical characteristics of 138 hospitalized patients with 2019 novel coronavirus-infected pneumonia in Wuhan, China. Jama. 2020;323(11):1061-9.

19. Zhu N, Zhang D, Wang W, Li X, Yang B, Song J, et al. A novel coronavirus from patients with pneumonia in China, 2019. New England Journal of Medicine. 2020;382:727-33.

20. Organization $\mathrm{WH}$. Infection prevention and control during health care when novel coronavirus ( $" \mathrm{nCoV})$ infection is suspected: Interim guidance. 2020: World Health Organization. 2020.

21. Guillin OM, Vindry C, Ohlmann T, Chavatte L. Selenium, selenoproteins and viral infection. Nutrients. 2019;11(9):2101.

22. Kańtoch M, Litwińska B, Szkoda M, Siennicka J. Importance of vitamin A deficiency in pathology and immunology of viral infections. Roczniki Panstwowego Zakladu Higieny. 2002;53(4):385-92.

23. Semba RD. Vitamin A and immunity to viral, bacterial and protozoan infections. Proceedings of the Nutrition Society. 1999;58(3):719-27.

24. Villamor E, Mbise R, Spiegelman D, Hertzmark E, Fataki M, Peterson KE, et al. Vitamin A supplements ameliorate the adverse effect of HIV-1, malaria and diarrheal infections on child growth. Pediatrics. 2002;109(1):e6.

25. Jee J, Hoet AE, Azevedo MP, Vlasova AN, Loerch SC, Pickworth CL, et al. Effects of dietary vitamin A content on antibody responses of feedlot calves inoculated intramuscularly with an inactivated bovine coronavirus vaccine. American Journal of Veterinary Research. 2013;74(10):1353-62.

26. West CE, Sijtsma SR, Kouwenhoven B, Rombout JH, DerZijpp AJV. Epithelia-damaging virus infections affect vitamin A status in chickens. The Journal of Nutrition. 1992;122(2):333-9.

27. Trottier C, Colombo M, Mann KK, JrMiller WH, Ward BJ. Retinoids inhibit measles virus through a type I IFN-dependent bystander effect. The FASEB Journal. 2009;23(9):3203-12.

28. Keil SD, Bowen R, Marschner S. Inactivation of M iddle $E$ ast respiratory syndrome coronavirus (MERS-C o V) in plasma products using a riboflavinbased and ultraviolet light-based photochemical treatment. Transfusion. 2016;56(12):2948-52.

29. Jones HD, Yoo J, Crother TR, Kyme P, Ben-Shlomo A, Khalafi R, et al. Nicotinamide exacerbates hypoxemia in ventilator-induced lung injury independent of neutrophil infiltration. PloS one. 2015;10(4):e0123460. 
30. Field CJ, Johnson IR, Schley PD. Nutrients and their role in host resistance to infection. Journal of Leukocyte Biology. 2002;71(1):16-32.

31. Galmés S, Serra F, Palou A. Vitamin E metabolic effects and genetic variants: A challenge for precision nutrition in obesity and associated disturbances. Nutrients. 2018;10(12):1919.

32. Beck MA, Kolbeck PC, Rohr LH, Shi Q, Morris VC, Levander OA. Vitamin E deficiency intensifies the myocardial injury of coxsackievirus B3 infection of mice. The Journal of Nutrition. 1994;124(3):345-58.

33. Beck MA. Increased virulence of coxsackievirus B3 in mice due to vitamin E or selenium deficiency. The Journal of Nutrition. 1997;127(5):966S-70S.

34. Cai C, Koch B, Morikawa K, Suda G, Sakamoto N, Rueschenbaum S, et al. Macrophage-derived extracellular vesicles induce long-lasting immunity against hepatitis $\mathrm{C}$ virus which is blunted by polyunsaturated fatty acids. Frontiers in immunology. 2018;9:723.

35. Begin M, Manku M, Horrobin D. Plasma fatty acid levels in patients with acquired immune deficiency syndrome and in controls. Prostaglandins, Leukotrienes and Essential Fatty Acids. 1989;37(2):135-7.

36. Pei J, Sekellick MJ, Marcus PI, Choi IS, Collisson EW. Chicken interferon type I inhibits infectious bronchitis virus replication and associated respiratory illness. Journal of Interferon and Cytokine Research. 2001;21(12):1071-7.

37. Turner RB, Felton A, Kosak K, Kelsey DK, Meschievitz CK. Prevention of experimental coronavirus colds with intranasal $a-2 b$ interferon. Journal of Infectious Diseases. 1986;154(3):443-7.

38. Morgenstern B, Michaelis M, Baer PC, Doerr HW, JrCinatl J. Ribavirin and interferon- $\beta$ synergistically inhibit SARS-associated coronavirus replication in animal and human cell lines. Biochemical and Biophysical Research Communications. 2005;326(4):905-8.

39. Kuri T, Zhang X, Habjan M, Martínez-Sobrido L, Garcia-Sastre A, Yuan Z, et al. Interferon priming enables cells to partially overturn the SARS coronavirusinduced block in innate immune activation. The Journal of General Virology. 2009;90(Pt 11):2686.

40. Matteucci C, Grelli S, Balestrieri E, Minutolo A, Argaw-Denboba A, Macchi B, et al. Thymosin alpha 1 and HIV-1: recent advances and future perspectives. Future Microbiology. 2017;12(2):141-55.

41. Costantini C, Bellet MM, Pariano M, Renga G, Stincardini C, Goldstein AL, et al. A Reappraisal of Thymosin Alpha1 in Cancer Therapy. Frontiers in Oncology. 2019;9:873.
42. Pica F, Gaziano R, Casalinuovo IA, Moroni G, Buè C, Limongi D, et al. Serum thymosin alpha 1 levels in normal and pathological conditions. Expert Opinion on Biological Therapy. 2018;18(sup1):13-21.

43. Gao Z, Zhu J, Sun Y, Ding X, Ma J, Cui Y, et al. Clinical investigation of outbreak of nosocomial severe acute respiratory syndrome. Zhongguo Weizhongbing Jijiuyixue $=$ Chinese Critical Care Medicine $=$ Zhongguo weizhongbing jijiuyixue. 2003;15(6):332-5.

44. Duchateau J, Delespesse G, Bolla K. Phase variation in the modulation of the human immune response. Immunology Today. 1983;4(8):213.

45. Renoux G. The general immunopharmacology of levamisole. Drugs. 1980;20(2):89-99.

46. Joffe M, Sukha N, Rabson A. Lymphocyte subsets in measles. Depressed helper/inducer subpopulation reversed by in vitro treatment with levamisole and ascorbic acid. The Journal of Clinical Investigation. 1983;72(3):971-80.

47. Bussel JB, Szatrowski TP. Uses of intravenous gammaglobulin in immune hematologic disease. Immunological Investigations. 1995;24(1-2):451-6.

48. Lew TW, Kwek TK, Tai D, Earnest A, Loo S, Singh K, et al. Acute respiratory distress syndrome in critically ill patients with severe acute respiratory syndrome. Jama. 2003;290(3):374-80.

49. Zhu N, Zhang D, Wang W, Li X, Yang B, Song J, et al. China Novel Coronavirus Investigating and Research Team. A novel coronavirus from patients with pneumonia in China, 2019. N Engl J Med. 2020;382(8):727-33.

50. Gralinski LE, Menachery VD. Return of the Coronavirus: 2019-nCoV. Viruses. 2020;12(2):135.

51. Zhou P, Yang XL, Wang XG, Hu B, Zhang L, Zhang W, et al. Discovery of a novel coronavirus associated with the recent pneumonia outbreak in humans and its potential bat origin. Bio Rxiv. 2020.

52. Guo H, Kota SH, Sahu SK, Hu J, Ying Q, Gao A, et al. Source apportionment of PM2. 5 in North India using source-oriented air quality models. Environmental Pollution. 2017;231:426-36.

53. Garaga R, Sahu SK, Kota SH. A review of air quality modelling studies in India: Local and regional scale. Current Pollution Reports. 2018;4(2):59-73.

54. Sahu SK, Kota SH. Significance of PM2. 5 air quality at the Indian capital. Aerosol Air Qual Res. 2017;17(2):588-97.

\section{SUMMARY}

- In Wuhan City, the province of Hubei, China, there appeared an unusual epidemic of pneumonia of uncertain etiology in December 2019 and the World Health Organisation (WHO) named it as COVID-19.

- As of May 9, 2020, more than 4,067,427 cases of COVID-19 and 278,467 deaths had been mentioned, of which most cases and deaths have occurred in USA followed by Spain and Italy and UK.

- On 30 January 2020, India confirmed the first outbreak of the COVID-19, pandemic from China. By $9^{\text {th }}$ May 2020, a total of 59,662 cases, 17,846 recoveries, 1 relocation and 1981 deaths were reported throughout the country by the Indian Council for Medical Research and the Ministry of Health and Family Welfare. As of 9 may, the most effected states are Maharashtra, Gujrat, Delhi and Tamil Nadu.

- The COVID-19 seems mostly transmitted through droplets by coughs and sneezes, unclean hands and by touching contaminated surfaces. They are also detected in stools and blood, which poses concerns about other transmission modes.

- The COVID-19 is preventing by restricting travel to high-risk locations, interacting with symptomatic persons. Basic hygiene steps, including regular washing of hands and the use of PPE, such as face masks, are also recommended.

- The dietary vitamins (Vitamins A, B, C and E) and immune enhancers (levamisole, thymopentin, interferons, gamma globulins) may help the immune system to fight against COVID-19.

- The lockdown strategy for controlling COVID-19 may also have some significant impact on pollution. The pollution control board of India has highlighted that there is a drastic change in air and surface water quality. 


\section{PICTORIAL ABSTRACT}

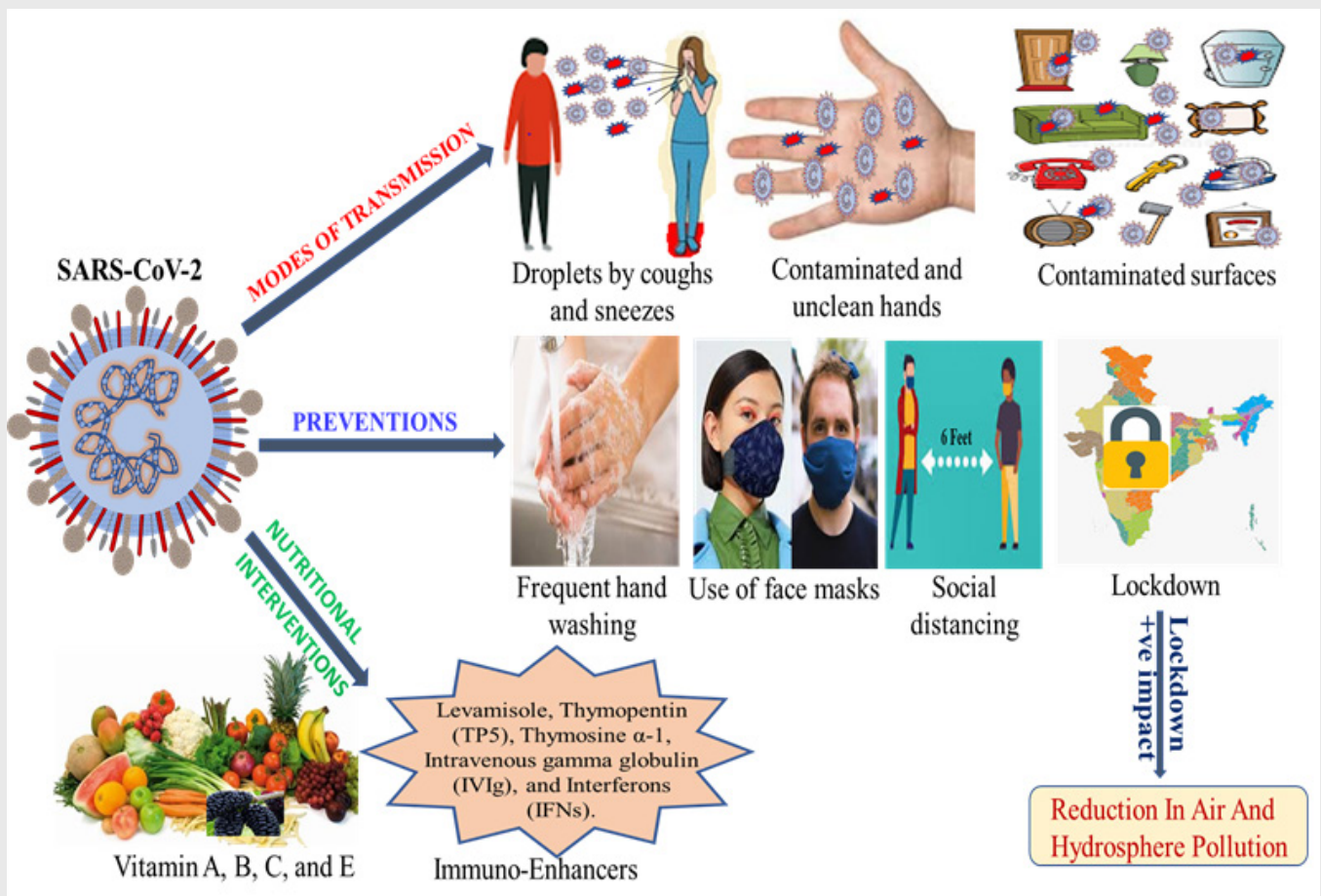

\section{About Authors}

Mr. Mohd Sajad has completed his post-graduation in Zoology from Dr. B R Ambedkar University, Agra. After that he has cleared CSIR-NET JRF in Life Sciences. Presently doing Ph. D in Centre for Interdisciplinary Research in Basic Sciences, Jamia Millia Islamia University, New Delhi. He has several research papers on his credit published in various peer reviewed national and international journals.

Cite this article: Sajad M, Ahmed M, Chand Thakur SC. An Outbreak of Severe Acute Respiratory Syndrome-2019 (COVID-19): A Major Health Concern. Indian J of Pharmaceutical Education and Research. 2020;54(4):847-57. 